\title{
ARTICLE
}

\section{The Landmark on Film: Representations of Place and Identity}

\author{
Pei-Sze Chow*
}

This paper examines two documentary essays focusing on landmark architecture in the transnational Øresund region comprising Copenhagen and Malmö. I argue that the motif of construction and deconstruction is congruous to our understanding of the ways identities are negotiated vis-à-vis spatial experience. In the films, the multiple trajectories of characters of diverse nationalities and cultures are woven into the (de)construction of the landmark structures, producing a visual space that interrogates what 'identity' means in an increasingly networked and global world.

In this paper I would like to explore filmed architecture as a mode of visually articulating the identities emerging from a transnational region. Here I focus on the cinematic representations of landmark architecture in the Øresund region that comprises the cities of Copenhagen and Malmö. I analyse two documentary essays by the Swedish filmmaker Fredrik Gertten that focus on landmark architectural projects in the region: Bye Bye Malmö (2002) and Gå På Vatten (2000). In these films, visual and aural elements both reconstruct and deconstruct the social relations emerging from the spatial dynamism of the transnational Øresund region. In my analysis I posit that the multiple histories of characters of diverse nationalities and cultures are woven into the (de)construction of the structures, producing a visual space that interrogates the meaning of 'identity' in an increasingly networked and global world. In the larger scheme of things, my project seeks to address the broader question of the ways in which films visualise social change.

\footnotetext{
* Department of Scandinavian Studies, UCL peisze.chow.11@ucl.ac.uk
}

Barbara Kosta writes that '[s]pace, and its myriad manifestations, shape and frame identities and produce affiliations, which are national, local, and transnational' (Kosta 2005: 345). In a similar vein Doreen Massey argues that space 'inherently implies the existence in the lived world of a simultaneous multiplicity of spaces; cross-cutting, intersecting, aligning with one another, or existing in relations of paradox or antagonism' (Massey 2005: 3). The two writers suggest that our lived, spatial experience of everyday life is composed of simultaneous spaces where meanings and identities overlap and interact. In this paper these two films about the Øresund are of interest because they capture a region in the process of becoming through a visual study of not only the architectural space of construction itself but also the social spaces of human interaction.

A key idea that runs through the films is 'construction'. Different layers of construction are apparent in the films: first, they literally document the physical construction of landmark architecture in the region and, in the case of one of the films, the dismantling or de-construction of a significant landmark. 
Second, on a metaphorical level, the films therefore also document the symbolic position of architecture in the negotiation and construction of transnational identities. Each film documents the web of human relationships surrounding the construction of different landmark architecture in the early 2000s. From a wider perspective they are an investigation into the social and spatial transformation of the Øresund region, and they feature narratives of national and transnational identities where the characters in the films negotiate their lived realities with respect to the architectural spaces in which the documentaries unfold. Therefore the documentaries raise the following questions: what identities and relationships are constructed by the people who are actually involved in the physical creation of the space? How is a sense of place negotiated in these contexts and communities? In other words, what social realities have they constructed for themselves vis-à-vis their relationships with the respective landmark architecture?

\section{Bye Bye Malmö}

Bye Bye Malmö (2002) is a sentimental study of one of Malmö's most visible landmark structures - the Kockums crane. The film does not simply chart the construction of a structure but rather the dismantling of this noted landmark that has stood as a geographical point of reference for a community for almost three decades. The 138-metre structure was located in the midst of the old shipyard in the Västra Hamnen (Western Harbour) district of Malmö. After its removal from the Malmö skyline the crane has since been reconstructed and brought back to life, as it were, in Ulsan, South Korea, which is currently the world's largest shipyard. Its removal was an emotional event for those who had organised their lives around the crane since its inception in 1974. While it fulfilled functional purposes as a ship-building tool and geographical landmark it was more importantly a symbol of the city's industrial rejuvenation after a major recession in the seventies. With the establishment of the Kockums shipyard and the crane's reputation as the largest in the world came widespread employment, immigration, and a bustling harbour city. Hence the crane is invested with much pride and significance for the people living around and with it. Indeed, the film demonstrates this aura through archival footage of the crane in the seventies, along with long shots of the crane standing tall and prominent in the skyline of Malmö.

Yet the late eighties saw the decline of Malmö's fortunes and the demise of its shipbuilding dominance. Kockums Industries was closed in 1986, and by the mid-nineties Malmö had the highest unemployment rate in Sweden. Hence Bye Bye Malmö is set in a contemporary environment where the hub of the shipbuilding industry has long since shifted to another part of the world and Malmö is in the midst of negotiating its postindustrial identity. As Malmö rebrands itself as part of the Øresund region and a city of knowledge and innovation the time has come for the crane, a relic of an industrial past, to be dismantled and removed from the city. My analysis is focused on the spaces of the crane's deconstruction as revealed on film, and I suggest that while this happens, in a contrary motion, peoples' stories and narratives recreate and reimagine an ephemeral anatomy of the structure. The narratives are thus concretised, as the film itself, into a visual and affective reconstruction of the essence of the landmark as an extension of social and place identity. Furthermore, the landmark's position in a global network is made apparent while it is being taken apart. The film presents us with several visual layers of social meaning, identity construction or location, and transitory flows of people across spaces. It also raises the question of the affective relationships between such architecture and lived experience: what are the marks that they leave behind (or not) on that space, as well as the emotional/psychological marks that are left on them by the space? Underneath all these layers of meaning, what lies at the essence of the space itself? What is left in 
the void? Hence two functions of the crane are made clear through the film: first, the crane as a site of belonging and memory, as a physical representation of a local, placed identity; and second, its space as part of the global network of capital flows is suggested through the multiplicity of voices laid over the work site.

At the beginning of the film there is an emphasis on disorientation. The film opens jarringly, with the uncomfortable metallic sounds of the tense steel wire cables whipping in the wind and the handheld camera seemingly disorientated while recording a panorama of Malmö from atop the crane. The camera then makes its way down, pausing at the control cab as the opening titles appear. Here, we are introduced to Paul, the crane's operator. There is an immediate jump cut to the ground level, to a shot of another character, George, looking steadily back up at the crane. This downward movement indicates a focus on the base or foundation of the crane, the space where the action of the drama, as it were, will take place. The seeming groundedness of the shot, however, gives way to instability and uncertainty as we learn that the crane is to be dismantled.

A sentimental tone is reflected in the documentary, particularly in the manner in which archival footage from the crane's bustling early heydays since 1974 is juxtaposed against the emptiness and derelict appearance of the shipyard towards the end of its life in Malmö. The removal of the crane parallels what seems to be the removal of Malmö from the global network of trade and commerce - the city's shipyard can no longer claim to house the largest crane in the world. As the old promotional video continues, the voice of the jaunty commentator changes to that of Gertten's, who, as a Malmö native, conveys a sombre nostalgia while he narrates: 'We recall 1974 as a happy time. The world's most modern shipyard. [...] Then came the crisis and the yard died.' A montage of various shots of quotidian life from different perspectives follows, always with the crane prominent in the background. Here, it is indeed significant that the archival footage is foregrounded, but its meaning here in the context of the documentary is unclear. Beyond expressing a certain nostalgia, the inclusion of the archival footage seems to suggest that even the visual memory of the past is at stake, and that preserving the images here in the documentary is the first act of preserving this memory, as it were.

The camera primarily follows George Wilson, the foreman from Scotland tasked to manage the entire project of dismantling the crane with a team of diverse nationalities. His narrative is interspersed with shots of the crane from various perspectives, as well as the path of the second primary character, Paul, the immigrant worker who used to operate the crane. Throughout the film the camera is invested with the ability to travel into, over, under, through the scaffolding and into the very anatomy of the structure, as it were, into the space of experiences and relationships. The camera allows us to experience and deconstruct the space and the role of the crane in the production of meaning, identity, and social dynamics. The way we experience the tearing down of the crane and seeing its constituent parts being dismantled and lowered to the ground is a meditative process, such that what the camera suggests is revealed are the layers of social discourses and structures of identity that have been built over the space, over time. It is in this deconstruction or deconstructed space that the various transnational communities and discourses interface. Even in its removal the crane still exists as a node where inter-national flows pass through, converge, or come into conflict, as conveyed by the various nationalities involved in the project. We have the Scottish project manager, a German team of crane dismantling specialists, the new South Korean owners of the crane, and the Yugoslavian crane operator. Most are transient characters that come into Malmö to work on this project, and when the job is done they leave for the next project in another part of the world. In fact, 
the narratives contained in the film and surrounding the crane form a very cosmopolitan constellation of transnational circulation. As the crane is being taken apart, its ephemeral presence still articulates varying configurations of interaction and social relationships between these groups of people.

One significant aspect of this constellation of relationships is the discourse of place and belonging that seems to be diminished within the larger discourse of global flows and spaces of transnational interaction. With respect to this, the most important character I want to draw out is Paul, the middle-aged immigrant-Swede who moved to Malmö from Yugoslavia as an eighteen-year-old to work at the shipyard and had worked as the crane's operator for almost the entire span of its existence. Paul's perspective plays a chief role in this documentary, as his emotional expression is the only one that we are completely privy to, and his relationship with the crane suggests that it is his anchor in Malmö. Its presence validates his sense of belonging to the city and provides a spatial context for bodily experience. In other words, Paul's place identity is entirely based on his relationship with the crane. The camera follows him into the crane's operating cab and to his apartment, where the crane is still a dominant object of reference. The documentary of the dismantling of the crane is thus also the documentary of Paul's eviction from his job. As the Scots joke about how Malmö's residents will now lose their way on the streets without the crane to guide their way home, Paul is one significant person who will be, in a sense, emotionally lost - with the loss of the crane, no further coordinates will guide his narrative beyond the film. It is also noteworthy that he, an accented and now-displaced immigrant (Naficy 2001), is the one who has had a wonderful panoramic view over the city for so many years and has operated the machinery so crucial to the city's identity. For Paul, his subjective experience reflects the sense that it is difficult for the postnational individual to locate himself in this contemporary nexus of global-local networks. As Paul traverses the boundary between immigrant and citizen, the crane functions suitably as an anchor point which provides a spatial context for bodily experience and where he imagines and re-imagines a sense of belonging to the place.

In other words, Paul's sense of belonging is mediated through the material presence of the crane, and his physical interaction with the space itself. An instance of Paul's engagement with subjective place construction through the crane is in the scenes of him looking out the window from his home. Even from his domestic space he maintains an affective connection with the crane - he enthusiastically reenacts for the camera how he typically has his breakfast every morning, seated at the table positioned just by the window, and he looks out wistfully into the far distance where the crane is situated amongst the other smaller structures around it. The viewer is also brought into this affective space through the camera's privileged perspective into Paul's experience ${ }^{1}$. The intensity of Paul's attachment in this short scene is expressed through the close-up of his facial changes whilst looking at the crane, which is framed by his window. The former expression of pride from claiming the best view of the crane from his breakfast table now turns to a melancholic sobriety at being reminded that this view will cease to exist when the crane is dismantled. Similarly, in another scene when the crane's operating cab is finally lowered to the ground, Paul steps into it with a nervous laugh at how strange it is to be in the cab on ground level. The scene is pregnant with sadness, and Paul walks into and around the cab, touching the levers and buttons on the control panel, and letting his hand trace the surface of the steel exterior of the cab with the awareness that this is the last time he will be part of the crane. He says to the camera, 'It has been a friend after all.' The viewer encounters Paul's emotions through an embodied experience when we watch him in this tactile, affective event with the crane. 
The film continues to explore how identity and belonging are mediated through embodied space, demonstrated through George. In his temporary office at the base of the crane he reveals his attachment to his hometown in Scotland through the desktop background image on his computer screen. Laura Marks makes an argument for the virtual image having a tangible connection to reality. She writes against the assumption that what is virtual must be immaterial, transcendent' and pursues the understanding that we desire the indexical and the real, and such virtual images, be they reality television shows, webcam video, all supply a material connection to the event (Marks 2002: 178). As a specialist who travels constantly from project to project around the world, the space of 'home' is thus compressed into a portable and virtual image of a house and expansive field. His place identity here is mediated through the computer screen - it seems that an indexical reproduction is enough to give him some solace amidst the chaos of his workplace.

The symbolic and affective power of the physicality of the crane in the city is expressed in this sympathetic description from a Bloomberg article:
A 128 meter-tall crane known as the 'Tears of Malmoe' towers above the Hyundai Heavy shipyard in Ulsan - a reminder of the fall of European ship- builders, who had dominated the industry until the 1980s. Hyundai Heavy bought it for $\$ 1$ from the now- gone Kockums $\mathrm{AB}$ shipyard in the Swedish city of Malmoe in 2002. Resi- dents of the city are said to have cried as they watched it depart, said Kim Miri, a Hyundai Heavy spokeswoman. (Cho 2007)

The Kockums Crane's 'departure' is described in a romantic manner, and from a foreigner's perspective, no less. While the film plainly lacks a native voice, where Gertten does not directly show us the reactions and sentiment from a Malmö or Swedish point of view but instead crafts a narrative that emerges from the relationship between these 'foreign voices' and the materiality of the crane.

The crane does not belong in Malmö anymore, and neither does it belong to Malmö. Malmö has now has moved on to rebrand itself as a cultural, middle-class cosmopolitan city, displacing those who were part of its shipbuilding heritage. Who, then, belongs in such a rebranded space? Hence it is significant and fitting that the crane's last job was to lift the pillars forming the foundations of the Øresundsbron (Øresund Bridge), another landmark structure that serves as an economic and social gesture of pan-Scandinavian or regional Nordic cooperation. This bridge is the subject of Gertten's next film, Gå På Vatten.

\section{Gå På Vatten}

From an architectural narrative located in the absence of one structure, this next film explores the space between neighbours - Copenhagen and Malmö. Gå På Vatten follows the construction in 2000 of the Øresundsbron, a 16 kilometre-long road and rail link between the two cities. In the film the physical bridge is interwoven with the mental/cultural bridges that are constructed via the personal narratives of those working on the construction site. The opening shot shows the film's title in Danish, and then the text subtly morphs into Swedish - unnoticed at first viewing, and it is understandably difficult to spot this minor change. It is as if to underline on this first textual level that the two peoples are bound together by a shared linguistic origin. Even the name of the bridge is a hybrid of both languages: 'Øresund' from the Danish and 'bron' from the Swedish.

At the start of the documentary Sven, a manager of the project on the Swedish side, speaks enthusiastically about the ideology behind the Øresundsbron project:

We are not only building one of the world's biggest stay cable bridges, but also the world's biggest immersed 
tunnel. We're building a big, artificial island. We're building a peninsula. Steel and concrete are exciting things for a builder. But that's not really the point. We're involved in building a new region. Sweden and Denmark are suddenly closer. Scania and Zealand are closer. Linking countries and people is what's important.

Yet mid-way through the film, in another scene where he prepares for a meeting with his Danish counterparts, he remarks on some cultural differences with a resigned tone: 'In Sweden we start work at eight o'clock. In Denmark they start at half past eight or quarter to nine. ... We work for forty hours, they work thirty-seven and a half.' He and his colleague go on to grouse about having to check every word in the documents and contracts with their Danish colleagues to make sure that every expression is articulated clearly and that there should be no misunderstandings despite the seeming similarity between the two languages: 'There are so many nuances. You think they don't exist, but they do.'

In the film the primary focus is on the relationships and tensions between the Danes and the Swedes, and their shared working space on the bridge's construction, which becomes a test-bed for the potentiality of a pan-Øresund community. As the bridge stretches further out into the Øresund and the concrete link between the two countries begins to take shape the film repeatedly juxtaposes serene images of the shared body of water against scenes that show the various characters unable to locate themselves in this new nexus of place-making. What language should they speak to each other? How do they reconcile differences in working attitudes and styles?

From the beginning there is already a strong sense that the two groups do not understand each other, and both sides are hesitant to reach out to the other. Characters from both sides start out with concerted efforts to define themselves against the other. For instance, the construction workers acknowledge some difficulty at understanding their 'foreign' colleagues. In particular, Janne, the Danish owner of the on-site lunch café, speaks vehemently about the Swedes and 'that horrible language of theirs'. There is the sense that Janne, like so many of the other workers on the construction site, is experiencing the initial confusion of having to negotiate her place in a landmark project meant to bridge national and cultural borders while still defining her own sense of cultural difference as a Dane. Morley and Robins write that encounters with globalisation provoke experiences of orientation and disorientation, and the production of 'placed and placeless identities':

The global-local nexus is associated with new relations between space and place, fixity and mobility, centre and periphery, 'real' and 'virtual' space, 'inside' and 'outside', frontier and territory. This, inevitably, has implications for both individual and collective identities and for the meaning and coherence of community. (Morley and Robins 1995: 121)

For Janne, navigating these new transnational relations and collective identities is made even more frustrating as she is the only woman in a male-dominated workplace. This added experience of gendered marginalisation is a compelling nuance to the way the space of the bridge project is deconstructed in the film. She complains of constantly being the object of male attention and of feeling trapped in the repetitive ennui of the everyday experience in the small café on the construction site. From a wider perspective, perhaps Janne's position as the only female on the site foregrounds the question of women's roles in the transnational network of cultural and economic exchange. Towards the end of the film we see her celebrating in a café with friends after being told that she has been selected to be on Expedition Robinson, a Danish reality television show that the American Survivor series is based on. 
While she celebrates her selection to be on the show as an escape from her job at the construction site, it is clear that she has only just exchanged the construction site for being marooned on a tropical island under the constant surveillance of the TV cameras. We last see her hermetically sealed within the television screen and frame, being monitored by the very same construction workers whom she complained briefly about before. Anders Linde-Laursen describes the 'hegemonic narrative' in Denmark in the 1930s: 'women's contribution to the respectability of the nation concerned the group oriented, private, emotional, family side of the community and its internal morals. Men had to perform individually, outwards, functionally, and manifest' (Linde-Laursen 2012: 170). It is interesting to note how the film suggests that even in the twenty-first century women still do not play a significant role in the construction of national and transnational identities.

Jill, a Swedish environmental activist opposing the construction of the bridge, is similarly marginalised from the discourse of the bridge, despite her dogged attempts to have her voice acknowledged as a legitimate part of this future Øresund community. She is clear about her social and political identity as well as her affiliation to the place: she wants to create and map out civic space via opposition and protest, yet at every turn, she is dismissed by not only engineers and workers but also society at large, which sends her to court for disrupting and trespassing on the construction site. Her narrative ends on a note of defeat and impotence as she breaks down in tears while gazing at the completed bridge from the Malmö side.

The women featured in the documentary therefore seem to exist in the margins of the site: they are made out to be extraneous and placeless individuals, either framed in a domesticised role - in the small lunch café like Janne or as curious wives of the workers visiting the site -presented as pornographic avatars pasted on the walls of the men's common rooms, or represented as social and political outcasts like Jill. In a region where its constituent countries dominate the top ten ranks of the World Economic Forum's Global Gender Gap Index (Hausmann, Tyson and Zahidi 2011) the film seems to suggest that not only the transnational market but also cultural production and the narrative of nation-building are spaces still dominated and constructed by men.

The film brings together each individual's personal spaces, memories, and experience, forming a cultural tapestry of sorts. Michael Rustin writes of the 'recognition that collective identities are formed through the common occupancy of space, and constituted in relations of particularist kinds' (Morley and Robins 1995: 39). The documentary problematizes these 'collective identities' and shows us several layers of identity construction that constantly morph at each stage of the construction process. Gertten's camera enters the shared spaces on the site - from the small on-site lunch café to the workers' personal quarters to the common room, and of course the work site. The characters also bring other spaces into the site - Stig's memories of former travels, images of Janne taking part in a reality TV show, Jill's political and environmental protest, and the construction worker Vagge's domestic relationship and promises of marriage and partnership. These spaces are expressed via narratives of disorientation and placelessness experienced by the characters followed by the camera.

Hence the bridge as portrayed in the film articulates a marked discourse of separation, more so than the intended unity it seeks to foster. On the metaphor of bridges Georg Simmel writes that " $t$ ] he bridge becomes an aesthetic value insofar as it accomplishes the connection between what is separated not only in reality and in order to fulfil practical goals, but in making it directly visible' (Simmel 1994: 6). The complexity of this filmic representation of the Øresundsbron certainly celebrates the effort accomplished by those involved in the project of linking together 
two peoples and constructing a new region, yet at the same time it highlights the acute fractures that occur underneath the veneer of commonality. Nevertheless these might be characterised as teething pains. Simmel further notes that the forms that dominate the dynamics of our lives are thus transferred [...] into the fixed permanence of visible creation' (Simmel 1994: 6). So as the bridge becomes less of a novelty and begins to be folded into quotidian experience the idea of an Øresund identity becomes more visible. A video commissioned in 2010 by the Øresundsbron management features an interview with a man named Peter Jurland, who identifies himself as an 'Øresund citizen' ten years after the bridge's inception: 'I live in Sweden and I work in Denmark, so I see myself more as an Øresund citizen. I can't really say I'm Danish, since I don't live in Denmark, and I can't say I'm Swedish, because I'm not' (Øresundsbron Consortium 2010). Jurland's experience echoes that of the many individuals who travel between the cities in just under twenty minutes, and who regard the bridge as a defining landmark for the Øresund region.

\section{Conclusion: reaching up and away}

In 2005 Gertten documented another landmark project located in Malmö - the Turning Torso, a residential skyscraper that has since become a prominent feature of the Øresund skyline. As in the previous documentaries, this project was not without conflict and tension. In Sossen, Arkitekten och det Skruvade Huset (The Socialist, The Architect, and the Twisted Tower, 2005) verticality is the key trope where the discourse of height and ambition informs the drama that unfolds on the ground. An ideological conflict emerges between two camps: on the one hand there are Santiago Calatrava, an internationally renowned 'global' architect of Spanish origin, and Johnny Örback, the idealist originator of the project and CEO of HSB (Hyresgästernas sparkasse), the Swedish housing association; on the other hand there is the stubbornly conservative local populace that reacts against the architectural project negatively. They regard the tower as a foreign object, preferring to see the skyscraper as impinging on their sense of what traditional Swedish housing should look like. The residential skyscraper is aligned with a very progressive, 'global' ethos, its design intentionally chosen to place Malmö in the exclusive network of 'global cities' with landmark architecture. The motivation is to rebrand Malmö as a 'global city', moving away from discussions of national identity or 'Swedishness'.

The tower now replaces the Kockums crane as a recognisable vertical landmark in Malmö's skyline now, but the meanings produced by the new structure differ vastly. While the narrative is primarily driven by the global-versus-local conflict occurring at the site of the construction, the arguments are frequently punctuated with sequences where the camera is climbing higher and higher up the scaffolding, surveying the surrounding land from the very top of the structure with a steady and critical eye, as if to suggest that the drama down below is of little significance when one is faced with the sheer magnitude of the tower's representational power - as a beacon of modernity in a postnational age. Like the Kockums crane, the construction of the tower serves as a node that connects the myriad human interactions that continue to be folded into the spatial experience of the region, despite the resistance from the ground. With the tower comes a sense of architecture reaching up and away from a discourse of the national, but instead projecting a different identity of place - the postnational. This sense of the postnational is very clearly expressed through the figure of Calatrava, whose voice dominates the documentary - the camera plays witness to his design process, his conversations to people all around the world in multiple languages, and the way he physically encounters the building site. As he narrates the building and speaks about the materials and the symbolism of the shape, the camera invests the building with a strong sense of coming 
alive at his words, and of belonging to a completely different category of architecture that Malmö has not yet experienced. The documentary ends in New York City at an architectural awards ceremony where the Turning Torso wins the Best Housing Project award, and finally Malmö is firmly accepted by the international community into the coveted network of global landmark architecture.

What the films unfold is the notion that architecture indeed plays the contextual, social function of scaffolding the formation of collective identities. The two films I analysed in this article deconstruct the 'simultaneous multiplicity of spaces' enmeshed in each respective edifice (Massey 2005: 3), revealing the affective connections that are constructed in the spaces people inhabit. The Kockums crane served as a psychological compass while the bridge representing an effort of regional place-making. And indeed, the camera makes visible what we cannot see when encountering whole architectural spaces. It is in the enmeshed spaces of the landmarks that the camera is able to penetrate, articulate, and deconstruct the network of relationships woven into the construction of these buildings.

\section{Notes}

1 Doreen Massey conceptualizes 'space' as a kind of surface upon which people, places, and culture is spread out [4]. Here, my understanding of 'affective space' is concerned with the subject's spatial experience - in this case, the field of Paul's embodied relationship with the crane and the cultural meanings produced through this relationship.

\section{References}

Cho, K B 2007 Korean Shipbuilders Hold Off China on Pricier Orders. Bloomberg. <http://www.bloomberg.com/apps/new s?pid=21070001\&sid=aDm.5.mEHJnU> [accessed 15 February 2012].
Gertten, F (dir.) 2002 Bye Bye Malmö. WG Film.

Gertten, F (dir.) 2005 Sossen, Arkitekten och det Skruvade Huset. WG Film.

Gertten, F and Westman L 2000 (dir.) Gå På Vatten. WG Film.

Hausmann R, Tyson, L D and Zahidi, S 2011 The Global Gender Gap Report 2011. World Economic Forum. Geneva. <http://www3.weforum.org/docs/WEF_ GenderGap_Report_2011.pdf> [accessed 16 February 2012].

Kosta, B 2005 Transcultural Space and Music: Fatih Akin's Crossing the Bridge: The Sound of Istanbul. In Fisher, J and Mennel, B (eds.) Spatial Turns: Space, Place, and Mobility in German Literary and Visual Culture. Amsterdam: Rodopi. p. 345.

Linde-Laursen, A 2012 Bordering: Identity Processes Between the National and Personal. Farnham: Ashgate. p. 170.

Marks, L 2002 Touch: Sensuous Theory and Multisensory Media. Minneapolis: University of Minnesota Press. p. 178.

Massey, D 2005 For Space. London: SAGE Publications. p. 3.

Morley, D and Robins, K 1995 Spaces of Identity: Global Media, Electronic Landscapes and Cultural Boundaries. London and New York: Routledge. p. 121.

Naficy, H 2001 An Accented Cinema: Exilic and Diasporic Filmmaking. Princeton and Oxford: Princeton University Press.

Øresundsbron Consortium 2010 ‘Crossing Over - 10 Years of the Øresund Bridge'. <http:// www.youtube.com/watch?v=g71KpjG3Bu0> [accessed 17 February 2012].

Simmel, G 1994 'Bridge and Door', in Theory, Culture \& Society 11 (1): 5-10. 